\title{
Ex Vitro Seedling Development from In Vitro Rhizome-Like Bodies in Eulophia promensis Lindl.: A New Technique for Orchid Propagation
}

\author{
Mohammad Musharof Hossain \\ Plant Tissue Culture \& Biotechnology Laboratory, Department of Botany, University of Chittagong, Chittagong 4331, Bangladesh \\ Correspondence should be addressed to Mohammad Musharof Hossain; musharof20bd@yahoo.com
}

Received 30 August 2014; Accepted 24 December 2014

Academic Editor: Urs Feller

Copyright @ 2015 Mohammad Musharof Hossain. This is an open access article distributed under the Creative Commons Attribution License, which permits unrestricted use, distribution, and reproduction in any medium, provided the original work is properly cited.

\begin{abstract}
This communication describes in vitro seed germination, embryo differentiation, and ex vitro seedling production from in vitro rhizome-like bodies of a terrestrial orchid, Eulophia promensis Lindl. Effects of two nutrient media, namely, Murashige and Skoog (MS) and Phytotechnology Orchid Seed Sowing medium $\left(\mathrm{P}_{723}\right)$ supplemented with 6-benzylaminopurine (BAP; $\left.0.5-1.0 \mathrm{mgL}^{-1}\right)$ and/or $\alpha$-naphthalene acetic acid (NAA; $\left.0.5-1.0 \mathrm{mgL}^{-1}\right)$ and activated charcoal $\left(2.0 \mathrm{gL}^{-1}\right)$, were studied on seed germination and subsequent development of embryos. Maximum seed germination (100\%) was recorded in $\mathrm{P}_{723}$ medium fortified with 1.0 mgL ${ }^{-1}$ $\mathrm{BAP}+2.0 \mathrm{gL}^{-1}$ activated charcoal. The different developmental stages of protocorm morphogenesis were traced out. In subsequent subcultures, the protocorms proliferated profusely and developed rhizome-like bodies (RLBs) with numerous hair-like structures. These RLBs were transferred to pots containing potting mixture composed of humus + coir dust + saw dust $(1: 1: 1)$ where $\sim 80 \%$ of RLBs survived and produced 1-3 seedlings per RLB. This is the first time report for in vitro germination of seeds and ex vitro seedling production from in vitro raised RLBs in Eulophia promensis. This is a time saving and cost effective protocol that could be extended to other economically important, rare, and endangered orchids for propagation and conservation.
\end{abstract}

\section{Introduction}

Orchids, the sovereign among ornamentals, attributed outstanding royalty in the world floricultural market and are one of the most important global cut flowers and potted floricultural crops. Orchidaceae is the largest family of the flowering plants consisting of about 30,000 species under $\sim 800$ genera. Due to weak reproductive barriers, over 1,06,000 attractive hybrids have already been developed and registered [1]. The world orchid trade exceeded billion dollars and countries of Asia-Pacific regions mainly Thailand, Singapore, and Malaysia dominated the world's floriculture market. In 2012, the global orchid trade among 40 exporting and 60 importing countries around the world was estimated at 504 million US dollars [2]. This figure undoubtedly indicates the necessity of production and improvement of orchids. Nowadays, commercial orchid seedlings are predominantly produced through tissue culture but these seedlings encountered a number of problems including high mortality and slow growth after transplantation from in vitro to greenhouse and difficulties in stimulating blooming in adult plants [3].

Eulophia promensis Lindl. (Eulophia geniculata King \& Pantl.), a rare terrestrial orchid of Bangladesh, has high demand in cut flower trade for its exquisite and perpetual flowers. Besides, it has high therapeutic importance in the traditional system of medicine. Crushed tubers and the extracted juice of Eulophia promensis are used as vermifuge [4]. Its tuber yields "salep" which is useful as a tonic and an aphrodisiac [5]. Unfortunately, many orchid species are disappearing at an alarming rate due to continuous destruction of natural habitats, unauthorized trade, and ruthless collections [6]. Furthermore, their high commercial demand has undoubtedly led to an increased emphasis on mass propagation and conservation of important orchids $[1,7]$. Therefore, a precise, simple, economical, rapidly multiplying, and highly reproducible protocol is required for conservation 
of orchids [8]. The major obstacles for mass propagation of economically important orchids, including Eulophia promensis, are (a) nonavailability of efficient and reliable protocols for seed germination, (b) lack of a clear understanding of early seedling growth and development, (c) high mortality of seedlings during transplantation from in vitro to in vivo conditions, (d) obligate requirement of mycorrhizal association for natural seed germination, (e) selection of suitable explants for micropropagation, and (f) scaling-up and automation of the techniques $[6,8]$. Ever since the discovery of asymbiotic germination of orchid seeds by Knudson [9], the technique has been used routinely for large scale propagation of economically important orchids [1, 10-14] but very few studies critically investigated the peculiarities of seed germination and protocorm development $[6,8,15-17]$ and no reports are available on regeneration of plants from in vitro seed derived rhizome-like bodies in ex vitro conditions. Keeping in mind the limitations and importance of mass propagation of orchids, the present studies were undertaken with a view to (i) develop an efficient protocol for germination of seeds, (ii) investigate the mode of morphogenesis of embryo during formation of protocorm and seedling development, and (iii) establish an efficient and easy technique for production of seedlings from in vitro seed derived rhizome-like bodies to ex vitro conditions in Eulophia promensis, an economically important and rare orchid of Bangladesh.

\section{Materials and Methods}

2.1. Planting Material and Initiation of Aseptic Cultures. Twothree-month-old green capsules of Eulophia promensis were collected from the naturally grown populations from the "Kata Pahar" area of the Chittagong University Campus of Bangladesh. These were washed thoroughly under running tap water and Teepol and then treated with $0.04 \%$ Bavistin and streptomycin sulphate solution for $20 \mathrm{~min}$ and washed three times with sterile distilled water. Subsequently these were subjected to surface sterilization treatment with $0.1 \%(\mathrm{w} / \mathrm{v}) \mathrm{HgCl}_{2}$ solution for 10 minutes with occasional agitation and washed thoroughly with sterile distilled water. Final disinfection was made by dipping the capsules in $70 \%$ ethanol for 30 seconds followed by washing with sterile distilled water. The sterilized capsules were flamed and split longitudinally with a sterile surgical blade and the seeds were inoculated on the surface of agar gelled nutrient media.

2.2. Culture Medium and Incubation Conditions. Two nutrient media, namely, Murashige and Skoog (MS) [18] and Phytotechnology Orchid Seed Sowing medium $\left(\mathrm{P}_{723}\right.$; PhytoTechnology Laboratories, Inc., USA) supplemented with 6benzylaminopurine (BAP; $0.5-1.0 \mathrm{mgL}^{-1}$ ) and $\alpha$-naphthalene acetic acid (NAA; $0.5-1.0 \mathrm{mgL}^{-1}$ ), either individually or in combinations, and two additives such as peptone and activated charcoal $\left(2.0 \mathrm{gL}^{-1}\right)$, were used for seed germination. The $\mathrm{pH}$ of the medium was adjusted to 5.8 prior to gelling with $0.8 \%$ agar and media were autoclaved at $121^{\circ} \mathrm{C}$ for 20 minutes at 15 psi. Culture vessels with inoculated seeds were maintained in a culture room where a cycle of $14 / 10 \mathrm{~h}$ continuous light $\left(60 \mu \mathrm{mol} \mathrm{m} \mathrm{m}^{2}\right)$ and dark conditions was maintained at $25 \pm 2^{\circ} \mathrm{C}$. After germination of seeds, protocorms were subcultured at 25-day interval.

2.3. Percent Seed Germination. After two weeks of inoculation, some of the seeds were taken out and dispersed in one drop of water on a glass slide and observed under light microscope. Percentage of germination was calculated employing the following formula:

number of seeds showing swelling of embryos $\times 100$

total number of seeds

Once the spherules were formed, observations were recorded at an interval of one week to trace different stages of embryo morphogenesis under stereozoom microscope.

2.4. Transfer of In Vitro Rhizome-Like Bodies to Ex Vitro Conditions. Rhizome-like bodies (RLBs) that developed from the germinated seeds were transplanted to pots containing a potting mixture composed of humus + coir dust + saw dust $(1: 1: 1)$ in such a way that the RLBs were fully covered with potting media and kept in shady moist place. Plantlets that developed from RLBs were finally transferred to community pots and kept in orchidarium.

2.5. Experimental Design and Statistical Analysis. A complete randomized block design (CRBD) was applied. The experiments were repeated thrice with maintaining five replicates per treatment for seed germination. For estimating seedlings production 10 RLBs were transplanted in each pot and five replicates were maintained. Means were separated by ANOVA and significant differences were assessed by Duncan's multiple range test at $P=0.05$ [19]. The statistical analyses were performed using the programme package Statistica ver. 7 (StatSoft, Tulsa, USA).

\section{Results and Discussion}

3.1. Seed Germination. The seeds germinated on all the nutrient media used (Table 1) but germination percentages varied depending on the media composition. Maximum seed germination (100\%) was recorded in $\mathrm{P}_{723}$ medium when fortified with $1.0 \mathrm{mgL}^{-1} \mathrm{BAP}+2.0 \mathrm{gL}^{-1}$ activated charcoal (Figure 1(a)). Species-specific media for seed germination have been reported in orchids [15]. The specificity was reported even within species of the same genus, for example, Mitra et al. [20] medium for Cymbidium macrorhizon [21], Nitsch and Nitsch medium for C. iridioides [22], and Knudson C for C. elegans [11]. The cause of maximum germination of seeds in $\mathrm{P}_{723}$ medium compared to MS medium could be due to the fact that $\mathrm{P}_{723}$ medium was enriched with peptone. Various complex substitutes including peptone with basal medium have been reported to improve seed germination and subsequent protocorm development in a number of orchids $[6,8,13,22,23]$. Peptone contains amino acids, amides, minor elements, and vitamins responsible for 
TABLE 1: Seed germination in Eulophia promensis.

\begin{tabular}{|c|c|c|c|c|c|c|}
\hline \multirow{2}{*}{ Medium } & \multicolumn{2}{|c|}{ PGRs $\left(\mathrm{mgL}^{-1}\right)$} & \multirow{2}{*}{ Additives $\left(2.0 \mathrm{gL}^{-1}\right)$} & \multicolumn{2}{|c|}{ Time (days) } & \multirow{2}{*}{ Seed germination $(\%)($ mean \pm SE) } \\
\hline & BAP & NAA & & Spherule & Protocorms & \\
\hline \multirow{6}{*}{ MS } & - & - & - & $25-30$ & $40-45$ & $73.00 \pm 1.20^{\mathrm{cd}}$ \\
\hline & - & 0.5 & - & $25-30$ & $45-50$ & $67.00 \pm 1.30^{\mathrm{cd}}$ \\
\hline & 0.5 & - & - & $20-25$ & $35-40$ & $78.00 \pm 1.25^{\mathrm{bc}}$ \\
\hline & 1.0 & 1.0 & - & $25-30$ & $40-45$ & $69.00 \pm 1.09^{\mathrm{cd}}$ \\
\hline & - & 1.0 & $\mathrm{AC}$ & $20-25$ & $40-45$ & $77.00 \pm 1.25^{\mathrm{bc}}$ \\
\hline & 1.0 & - & $\mathrm{AC}$ & $20-25$ & $35-40$ & $85.00 \pm 2.30^{\mathrm{ab}}$ \\
\hline \multirow{6}{*}{ P723 } & - & - & - & $20-25$ & $40-45$ & $95.50 \pm 2.30^{\mathrm{b}}$ \\
\hline & - & 0.5 & - & $25-30$ & $45-50$ & $68.00 \pm 2.30^{\mathrm{cd}}$ \\
\hline & 0.5 & - & - & $20-25$ & $35-40$ & $95.00 \pm 1.75^{\mathrm{b}}$ \\
\hline & 1.0 & 1.0 & - & $25-30$ & $35-40$ & $70.00 \pm 1.69^{\mathrm{cd}}$ \\
\hline & - & 1.0 & $\mathrm{AC}$ & $20-25$ & $40-45$ & $96.50 \pm 1.30^{\mathrm{b}}$ \\
\hline & 1.0 & - & $\mathrm{AC}$ & $20-25$ & $30-35$ & $100.50 \pm 2.00^{\mathrm{a}}$ \\
\hline
\end{tabular}

Mean values within a column followed by the same letter were not significantly different at $P=0.05$.

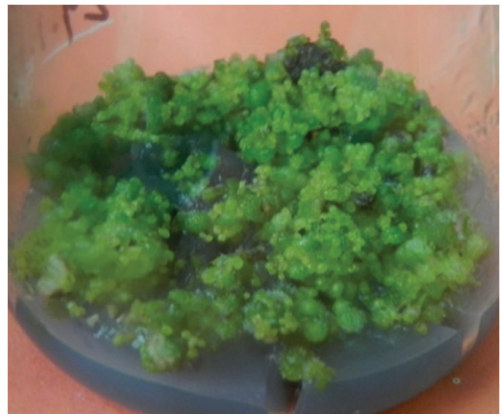

(a)

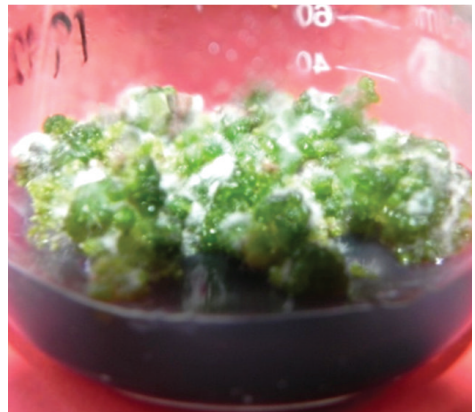

(b)

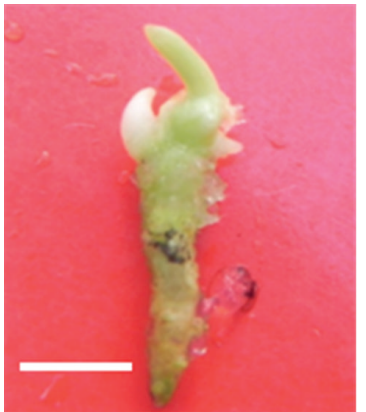

(c)

FIGURE 1: Germination of seeds of Eulophia promensis: (a) development of protocorms, (b) protocorms proliferated to form rhizome-like bodies (RLBs), and (c) an individual RLB.

enhancement of seed germination and growth of protocorms [24]. Beneficial effects of activated charcoal on seed germination and protocorm development have also been accounted for in orchid tissue culture for its high adsorption affinity to excessive and inhibitory compounds. Activated charcoal is known to adsorb morphogenetically active or toxic substances such as 5-hydroxymethylfurfural, which is produced by the dehydration of sucrose during autoclaving, and inhibitory phenolics and carboxylic compounds produced by the tissues and excessive hormones and vitamins in the media [25-29]. BAP is known to enhance germination frequency in Cypripedium spp. [30], Eulophia dabia, and Pachystoma senile and stimulated protocorm multiplication as well as shoot formation in Cymbidium pendulum [31] and Cattleya aurantiaca [32].

3.2. Morphogenesis of Embryo and Seedling Development. The protocorms proliferated in germination media but these did not develop seedlings after prolonged culture (>three months). However, in subsequent subcultures these developed long rhizome-like bodies (RLBs) with numerous hairs on the surface and a beak-like structure at their tip region indicating the growing shoot (Figures 1(b) and 1(c)). Germination of orchid seeds followed a peculiar metamorphogenetic pathway; that is, undifferentiated embryos swelled up by absorbing water and nutrients from the media and developed a compact mass of parenchymatous cells called spherule which gradually develop protocorm, an intermediate structure between seed and seedling [33]. At the initial stage of protocorm development, an appendicle, looking like a closed ridge, appeared at the upper part of the protocorms which leads to shoot formation while basal part escorts root development $[6,8,13,14]$. In E. promensis a different type of morphogenesis was observed. In this case, the protocorms became elongated and formed rhizome-like bodies (RLBs) with numerous hairs and some growth appendages on the body surface and a growing tip indicating the development of leafy shoots and the root initials, respectively (Figures 2(a)2(f)). Formation of RLBs in in vitro protocorms has also been reported in a terrestrial orchid, Geodorum densiflorum [34]. Each RLB produced 1-3 seedlings within two months of transfer to outside pots containing potting mixture composed 


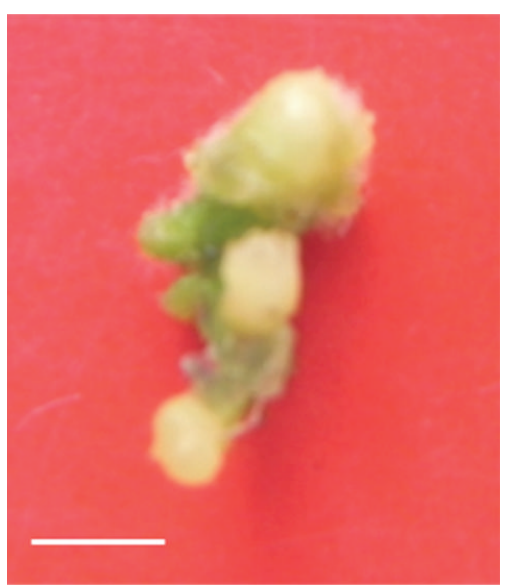

(a)

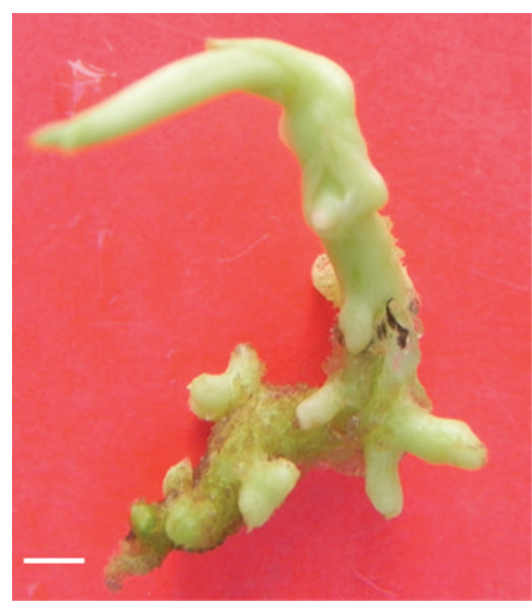

(d)

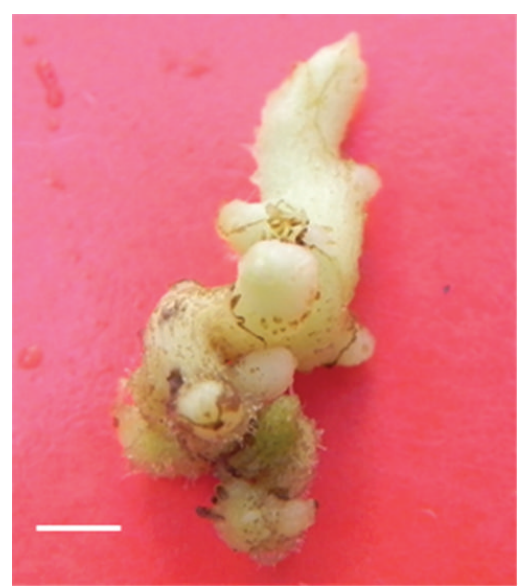

(b)

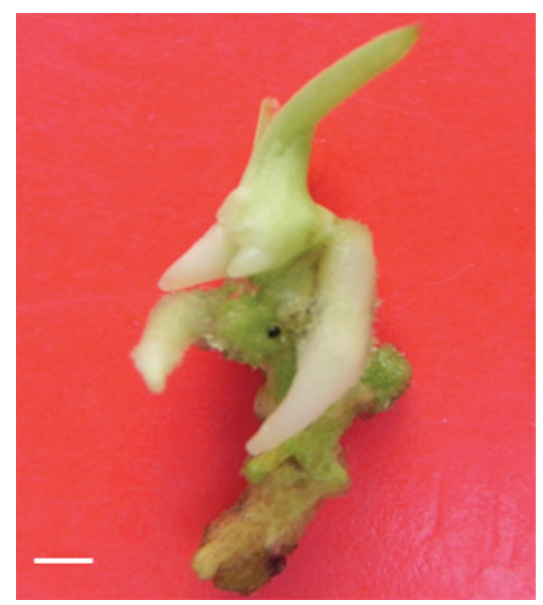

(e)

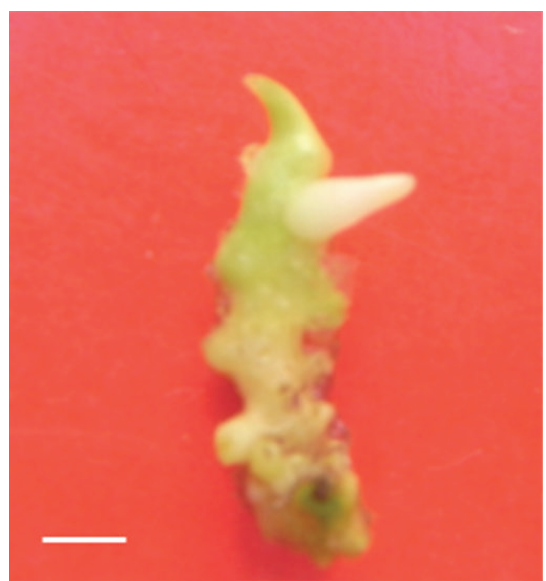

(c)

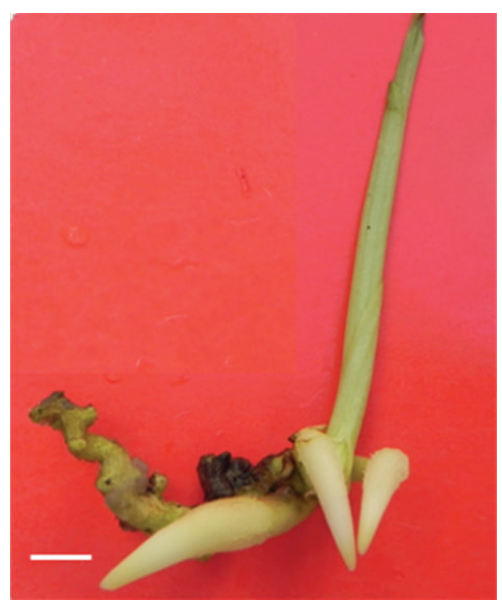

(f)

FIGURE 2: Protocorm morphogenesis and seedling formation in Eulophia promensis: (a) proliferation of protocorm, (b) RLB with numerous hairs and appendices, (c) RLB with root and growing shoot, and (d)-(f) development of RLB to seedling.

of humus + coir dust + saw dust $(1: 1: 1)$. These were finally transferred to community pots (Figures $3(\mathrm{a})-3(\mathrm{c})$ ). In the potting mixture the seedlings produced $1.0-1.5 \mathrm{~cm}$ size oblong-rotund pseudobulbs at the base of the plants and the aboveground part died after six to seven months and the pseudobulbs remained dormant for about six months. In the following year new shoots were regenerated from the underground pseudobulbs (Figures 3(d) and 3(e)). The plants produced in this way flowered after three years from seed germination (Figure 3(f)). In general production of orchid seedlings through in vitro seed culture is completed by germination of seeds, development of seedlings, elongation of seedlings, induction of stout root system, and transfer of seedlings to outside environment through successive phase of acclimatization. Plantlets produced in vitro often show physiological and anatomical deficiencies, low photosynthesis rate, and incomplete autotrophy and are unable to develop resistance against major and minor microbial pathogens [35]. Moreover, survival of asymbiotically raised orchid seedlings transferred directly to natural habitats is unsuccessful until and unless they developed mycorrhizal associations. When in vitro plantlets are transplanted from culture room to greenhouse conditions they may desiccate or wilt rapidly and die as a result of the change in environment, unless substantial precautions are taken to adapt these to new environment. Acclimatization of in vitro grown plantlets to ex vitro environment by gradual weaning towards ambient relative humidity and light levels facilitates better survival of the young tender plantlets [36, 37]. Therefore, in vitro raised plantlets must undergo a period of acclimatization, more specifically, a period of transitional development to correct the anatomical abnormalities and develop physiological performance for survival in ex vitro conditions. Thus the novelty of the present study is that the protocol developed for seedling production in E. promensis alleviated the above limitations.

\section{Conclusions}

This is the first report for in vitro germination of seeds of $E$. promensis and seedling production from in vitro rhizome-like 


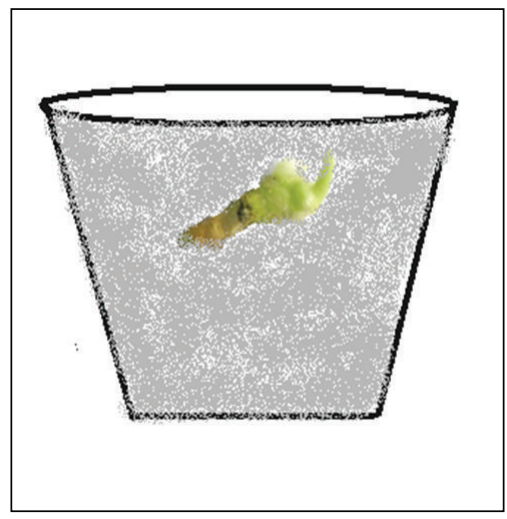

(a)

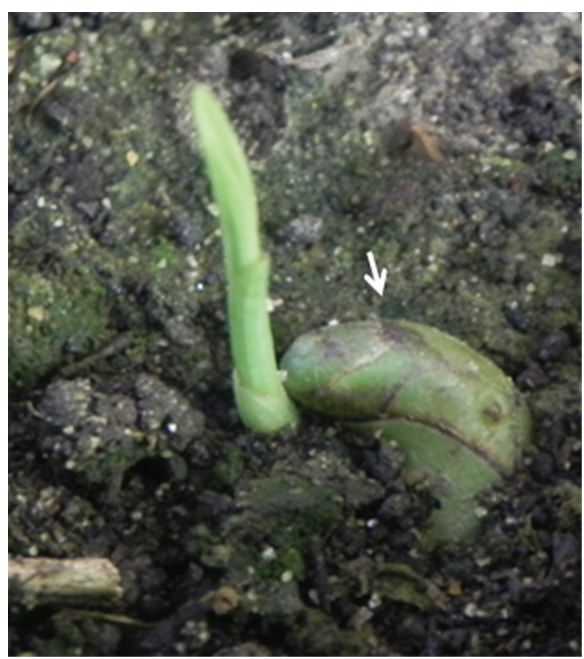

(d)

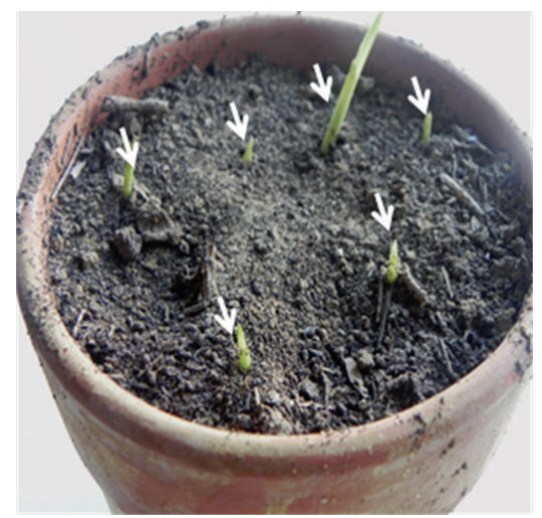

(b)

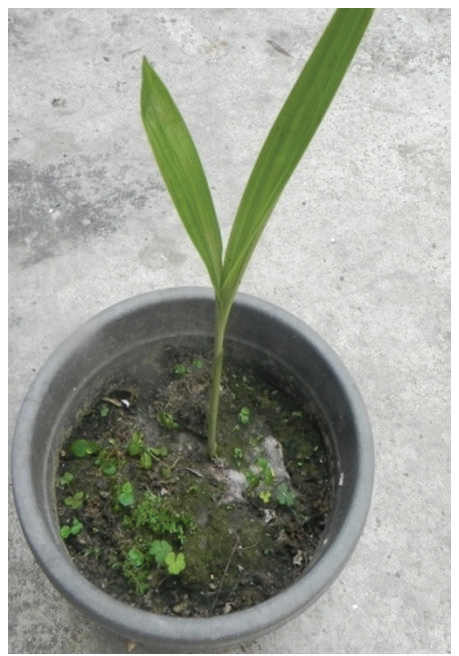

(e)

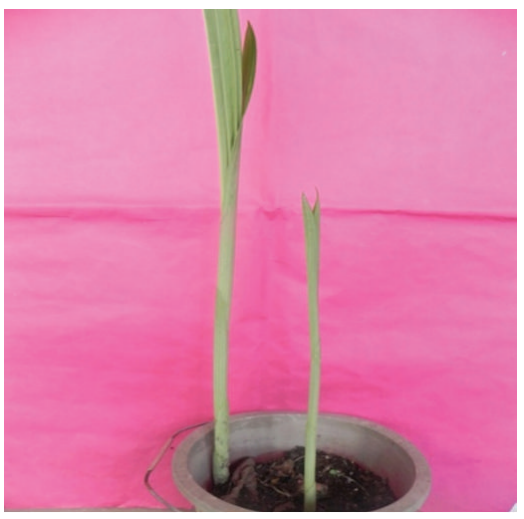

(c)

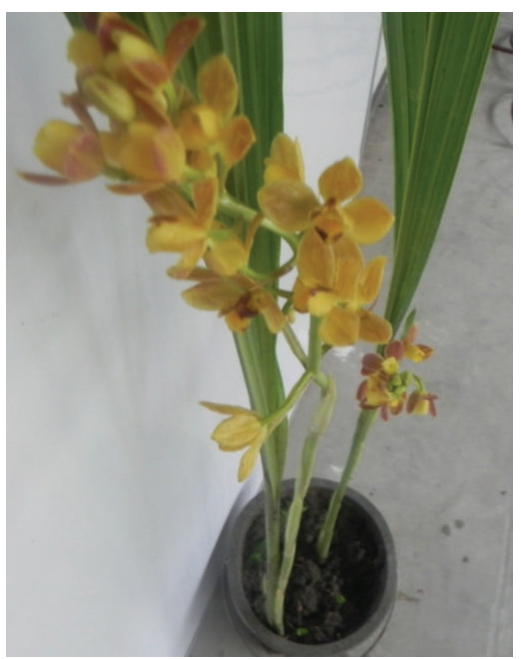

(f)

FIGURE 3: Seedling production in Eulophia promensis from in vitro RLBs under ex vitro conditions: (a) transplantation of RLB to pot, (b) sprouting of RLBs (arrow), (c) young seedlings (1st generation), (d)-(e) sprouting of dormant rhizome (arrow) in the next year, and (f) flowering of three-year-old plants produced from in vitro RLBs.

bodies in ex vitro conditions. The technique developed for E. promensis is a time saving and cost effective protocol that could be extended to other economically important, rare, and endangered orchids for propagation and conservation.

\section{Abbreviations}

BAP: 6-Benzylaminopurine

NAA: $\alpha$-Naphthalene acetic acid

RLBs: Rhizome-like bodies

MS: Murashige and Skoog medium

$\mathrm{P}_{723}$ : Phytotechnology Orchid Seed Sowing medium.

\section{Conflict of Interests}

The author declares that there is no conflict of interests regarding the publication of this paper.

\section{Acknowledgment}

The author acknowledges the Ministry of Education, Bangladesh, for providing financial support under grants for Advanced Research in Sciences.

\section{References}

[1] M. M. Hossain, R. Kant, P. T. van, B. Winarto, S. Zeng, and J. A. Teixeira da Silva, "The application of biotechnology to orchids," Critical Reviews in Plant Sciences, vol. 32, no. 2, pp. 69-139, 2013.

[2] A. Cheamuangphan, C. Panmanee, and R. Tansuchat, "Value chain analysis for orchid cut flower business in Chiang Mai," Business and Information, pp. 712-721, 2013.

[3] M. Li, Studies and Applications of Orchid Mycorrhizal Fungi, University of Yunnan Press, Kunming, China, 2006.

[4] H. J. Chowdhery, Orchid Flora of Arunachal Pradesh, Bishen Singh Mahaendra Pal Singh, Dehra Dun, India, 1998. 
[5] C. P. Khare, Indian Medicinal Plants: An Illustrated Dictionary, Springer, Berlin, Germany, 2007.

[6] M. M. Hossain, M. Sharma, and P. Pathak, "Cost effective protocol for in vitro mass propagation of Cymbidium aloifolium (L.) Sw.- a medicinally important orchid," Engineering in Life Sciences, vol. 9, no. 6, pp. 444-453, 2009.

[7] M. L. Stenberg and M. E. Kane, "In vitro seed germination and greenhouse cultivation of Encyclia boothiana var. Erythronioides, an endangered Florida orchid," Lindleyana, vol. 13, pp. 101-112, 1998.

[8] M. M. Hossain, M. Sharma, J. A. T. da Silva, and P. Pathak, "Seed germination and tissue culture of Cymbidium giganteum Wall. ex Lindl," Scientia Horticulturae, vol. 123, no. 4, pp. 479-487, 2010.

[9] L. Knudson, "Nonsymbiotic germination of orchid seeds," Botanical Gazette, vol. 73, no. 1, pp. 1-25, 1922.

[10] S. K. Sharma and P. Tandon, "Influence of growth regulators on asymbiotic germination and early development of Coelogyne punctulata Lindl," in Biology, Conservation and Culture of Orchids, S. P. Vij, Ed., pp. 441-451, Affiliated East West Press, New Delhi, India, 1986.

[11] S. K. Sharma and P. Tandon, "Asymbiotic seed germination and seedling growth of Cymbidium elegans Lindl. and Coelogyne punctulata Lindl. as influenced by different carbon sources," Journal of the Orchid Society of India, vol. 4, pp. 83-87, 1990.

[12] H. Shimura and Y. Koda, "Enhanced symbiotic seed germination of Cypripedium macranthos var. rebunense following inoculation after cold treatment," Physiologia Plantarum, vol. 123, no. 3, pp. 281-287, 2005.

[13] M. M. Hossain, M. Sharma, and P. Pathak, "In vitro propagation of Dendrobium aphyllum (Orchidaceae) - seed germination to flowering," Journal of Plant Biochemistry and Biotechnology, vol. 22, no. 2, pp. 157-167, 2013.

[14] M. M. Hossain and R. Dey, "Multiple regeneration pathways in Spathoglottis plicata Blume-a study in vitro," South African Journal of Botany, vol. 85, pp. 56-62, 2013.

[15] J. Arditti and R. Ernst, "Physiology of germinating Orchid seeds," in Orchid Biology: Reviews and Perspectives-III, J. Arditti, Ed., pp. 177-222, Cornell University Press, New York, NY, USA, 1984.

[16] T. B. Batygina, E. A. Bragina, and V. E. Vasilyeva, "The reproductive system and germination in orchids," Acta Biologica Cracoviensia Series Botanica, vol. 45, no. 2, pp. 21-34, 2003.

[17] M. M. Hossain, "In vitro embryo morphogenesis and micropropagation of Dendrobium aggregatum Roxb," Plant Tissue Culture and Biotechnology, vol. 23, no. 2, pp. 241-249, 2013.

[18] T. Murashige and F. Skoog, "A revised medium for rapid growth and bioassays with tobacco tissues cultures," Physiologia Plantarum, vol. 15, no. 3, pp. 473-497, 1962.

[19] D. B. Duncan, "Multiple range and multiple F test," Biometrics, vol. 11, pp. 1-42, 1955.

[20] G. C. Mitra, R. N. Prasad, and A. Roychowdary, "Inorganic salts and differentiation of protocorms in seed-callus of an orchid and correlated changes in its free amino acid content," Indian Journal of Experimental Biology, vol. 14, pp. 350-351, 1976.

[21] S. P. Vij and P. Pathak, "Asymbiotic germination of the saprophytic orchid, Cymbidium macrorhizon: a study in vitro," Journal of the Orchid Society of India, vol. 2, pp. 25-32, 1988.

[22] C. Jamir, J. Devi, and P. C. Deka, "In vitro propagation of Cymbidium iridiodes and C. lowianum," Journal of the Orchid Society of India, vol. 16, pp. 83-89, 2002.
[23] S. P. Vij, A. Sood, and K. K. Plaha, "In vitro seed germination of some epiphytic orchids," in Contemporary Trends in Plant Science, S. C. Verma, Ed., pp. 473-481, Kalyani Publishers, New Delhi, India, 1981.

[24] P. T. Krishna-Mohan and S. M. Jorapur, "In vitro seed culture of Acampe praemorsa (Roxb.) Blatt. and McC," in Biology, Conservation and Culture of Orchids, S. P. Vij, Ed., p. 437, Affiliated East West Press, New Delhi, India, 1986.

[25] A. P. Oliva and J. Arditti, "Seed germination of North American orchids. II. Native California and related species of Aplectrum, Cypripedium, and Spiranthes," Botanical Gazette, vol. 145, no. 4, pp. 495-501, 1984.

[26] B. Klein and M. Bopp, "Effect of activated Charcoal in agar on the culture of lower plants," Nature, vol. 230, no. 5294, p. 474, 1971.

[27] G. Fridborg and T. Eriksson, "Effects of activated charcoal on growth and morphogenesis in cell cultures," Physiologia Plantarum, vol. 34, no. 4, pp. 306-308, 1975.

[28] G. Fridborg, M. Pedersen, L.-E. Landstrom, and T. Eriksson, "The effect of activated charcoal on tissue cultures: adsorption of metabolites inhibiting morphogenesis," Physiologia Plantarum, vol. 43, no. 2, pp. 104-106, 1978.

[29] M. A. Weatherhead, J. Burdon, and G. G. Henshaw, "Some effects of activated charcoal as an additive to plant tissue culture media," Zeitschrift für Pflanzenphysiologie, vol. 89, no. 2, pp. 141147, 1978.

[30] M. A. de Pauw, W. R. Remphrey, and C. E. Palmer, "The cytokinin preference for in vitro germination and protocorm growth of Cypripedium candidum," Annals of Botany, vol. 75, no. 3, pp. 267-275, 1995.

[31] P. Pathak, K. C. Mahant, and A. Gupta, "In vitro propagation as an aid to conservation and commercialization of Indian orchids: seed culture," in Orchids: Science and Commerce, P. Pathak, R. N. Sehgal, N. Shekhar, M. Sharma, and A. Sood, Eds., pp. 319-362, Bishen Singh Mahendra Pal Singh, Dehra Dun, India, 2001.

[32] R. L. M. Pierik and H. H. M. Steegmans, "The effect of 6benzylamino purine on growth and development of Cattleya seedlings grown from unripe seeds," Zeitschrift für Pflanzenphysiologie, vol. 68, no. 3, pp. 228-234, 1972.

[33] G. Leroux, D. Barabé, and J. Vieth, "Morphogenesis of the protocorm of Cypripedium acaule (Orchidaceae)," Plant Systematics and Evolution, vol. 205, no. 1-2, pp. 53-72, 1997.

[34] S. K. Bhadra and M. M. Hossain, "In vitro germination and micropropagation of Geodorum densiflorum (Lam.) Schltr.an endangered orchid species," Plant Tissue Culture, vol. 13, pp. 165-171, 2003.

[35] A. Pandey, N. Bag, B. Chandra, and L. M. S. Palni, "Biological hardening: a promising technology for tissue culture industry," in Role of Plant Tissue Culture in Biodiversity Conservation and Development, S. K. Nandi, L. M. S. Palni, and A. Kumar, Eds., pp. 565-577, Gyanodaya Prakashan, Nainital, India, 2002.

[36] Y. J. Yoon, M. Mobin, E. J. Hahn, and K. Y. Paek, "Impact of in vitro $\mathrm{CO}_{2}$ enrichment and sugar deprivation on acclimatory responses of Phalaenopsis plantlets to ex vitro conditions," Environmental and Experimental Botany, vol. 65, no. 2-3, pp. 183-188, 2009.

[37] S. Cha-um, B. Ulziibat, and C. Kirdmanee, "Effects of temperature and relative humidity during in vitro acclimatization, on physiological changes and growth characters of Phalaenopsis adapted to in vivo," Australian Journal of Crop Science, vol. 4, no. 9, pp. 750-756, 2010. 

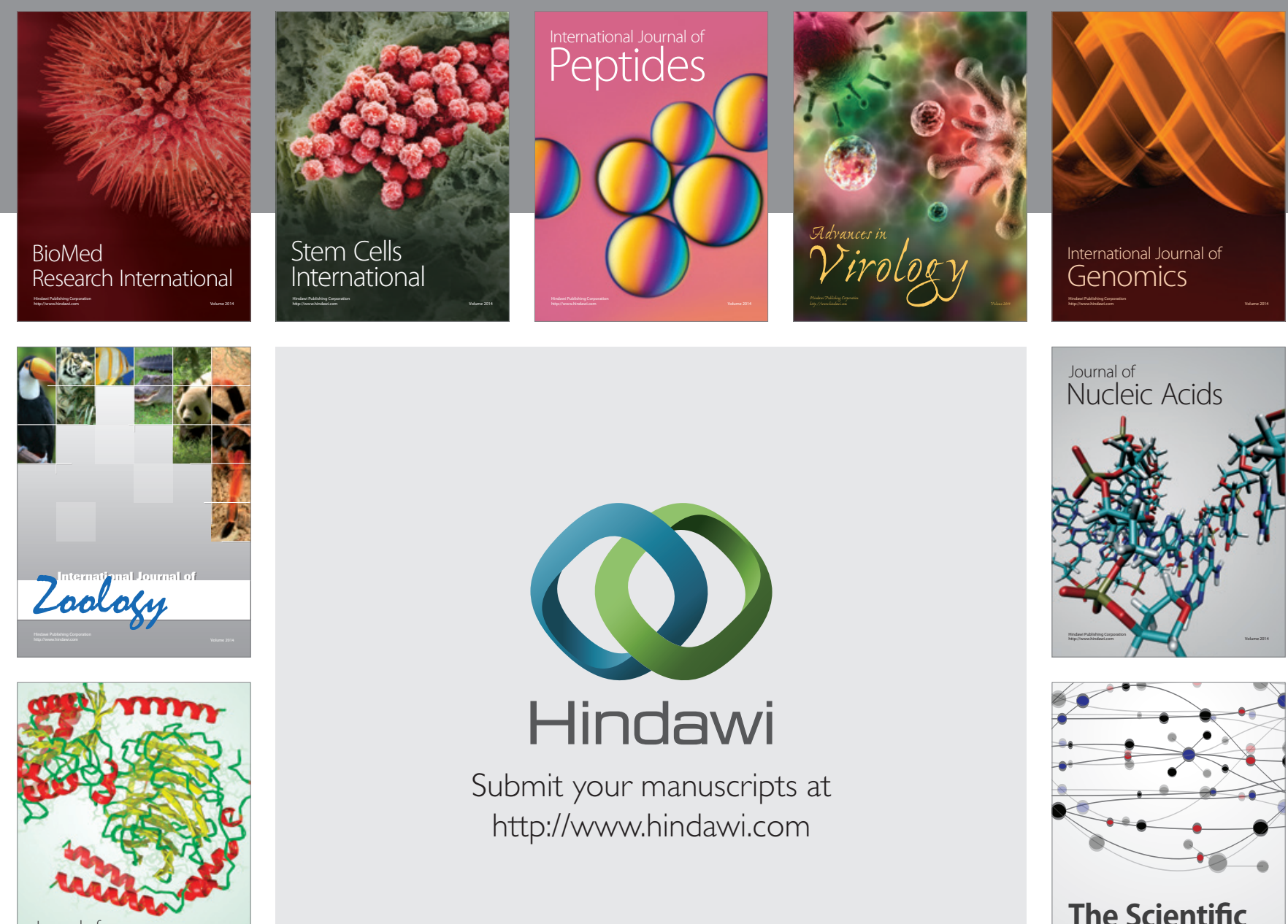

Submit your manuscripts at

http://www.hindawi.com

Journal of
Signal Transduction
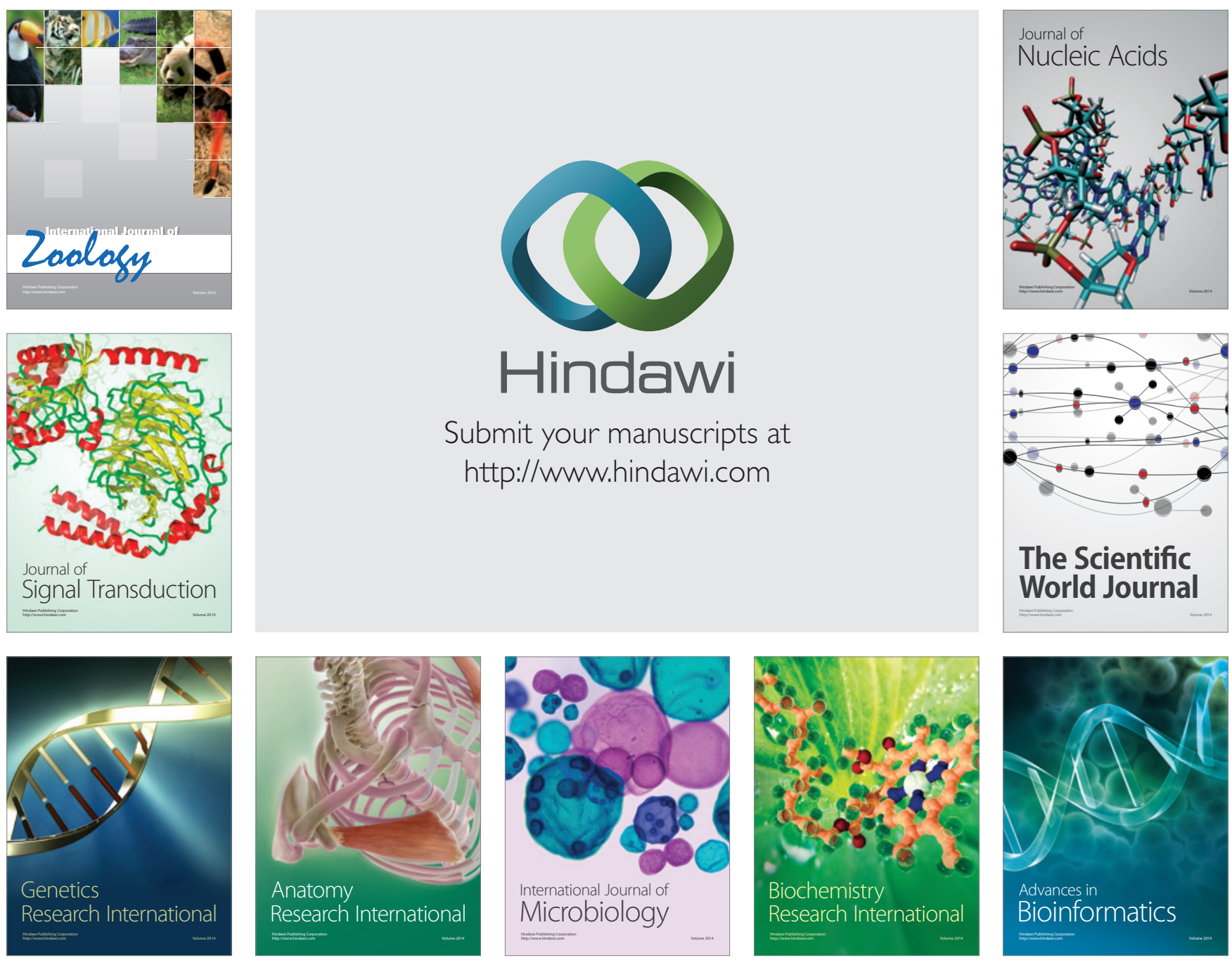

The Scientific World Journal
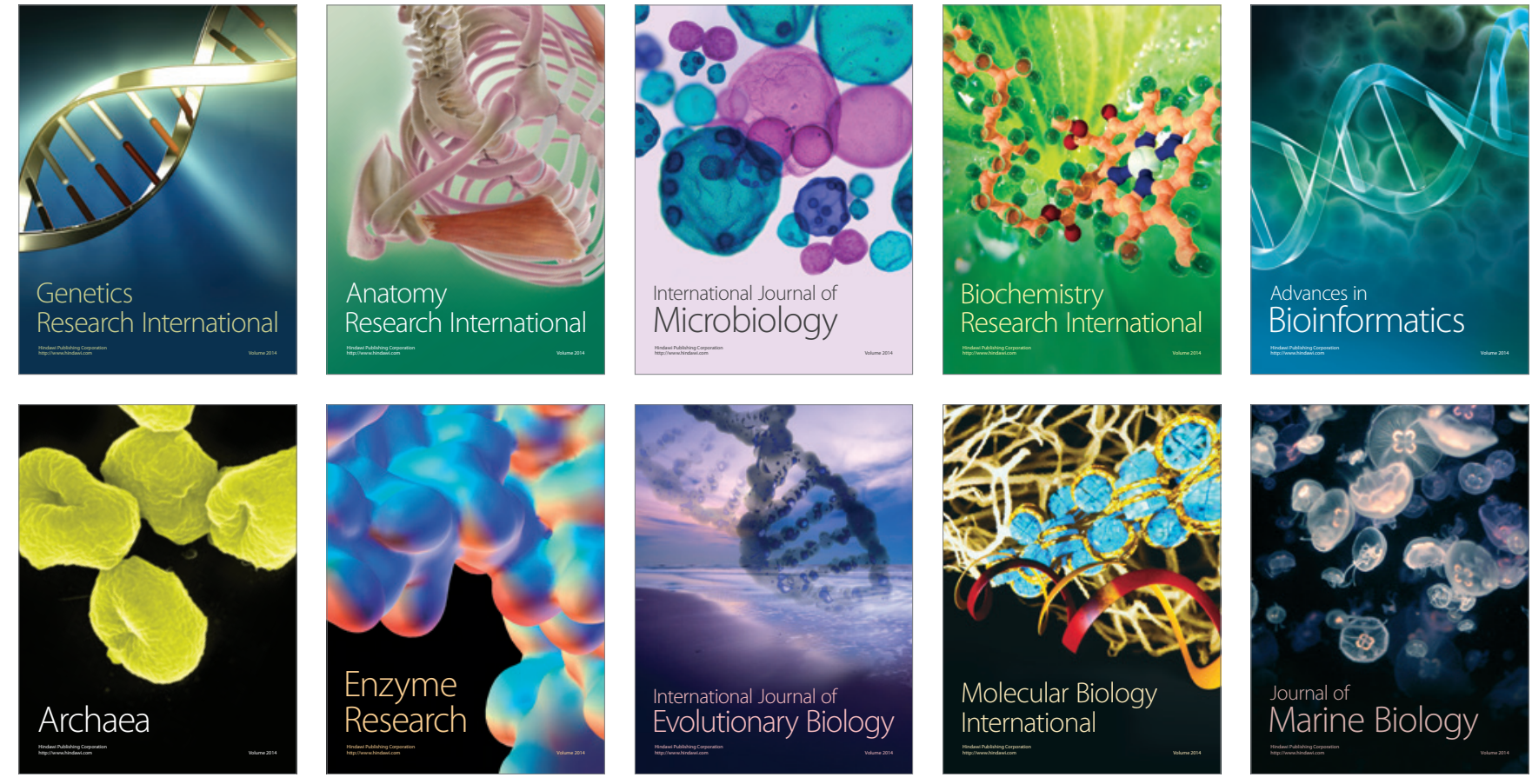